\title{
Las Normas Pastorales y el Nuevo Ritual del sacramento de la reconciliación
}

\author{
A. ¿Deberán interpretarse de forma juridico-canónica?
}

No cabe duda que todos nos hemos tomado la molestia de leer detenidamente tanto las Normas Pastorales como el Nuevo Ritual ${ }^{\text {. }}$.

\begin{abstract}
1. Acta Apostolicae Sedis 64 (1972) 510-514.
"Normas Pastorales para dar la absolución sacramental general": Pastoral Litúrgica n. $.^{\circ} 68-70,19-24$; J. MEDINA, "Un nuevo Documento de Ia S. Sede sobre el sacramento de la penitencia": Teología $y$ Vida 13 (1972) 107-117; "Normas Pastorais para a Absolvicao Sacramental Geral.": Revista Ecclesiastica Brasileira 32 (1972) 672-674 a las que sigue "Principios e Orientaçoes para Renovaçao da Pastoral da Penitência": Revista Ecclesiastica Brasileira 32 (1972) 676-684. Estas orientaciones son debidas a la Comisión Nacional de Liturgia Brasileña y han sido aprobadas por la Comisión Episcopal del citado país; H. WAGNon, "Les "Normes pastorales" pour l'administration de l'absolution sacramentelle genérale": Revue Théologique de Louvain 4 (1973) 46-57; M. DESDutTs, "L'absolution collective. Commentaire des "Normes pastorales" de la $\mathbf{S}$. Congrégation pour la Doctrine de la Foi": Esprit et Vie 83 (1973) 103-108; K. RAHNER, "Bussandacht und Einzelbeichte. Anmerkungen zum römischen Erlass über das Bussakrament": Stimmen der Zeit 97 (1972) 363-372; Les nouvelles Normes pour l'absolution generale": La Documentation Catholique 69 (1972 n. ${ }^{1}$ 614) 704-705. "Normas renovadoras de la confesión. Para profundizar en una mayor reconciliación con Dios y con nuestros hermanos": Ecclesia 34 (1974, n. ${ }^{\circ}$ 1.682) 316-327; "La reforma insiste en el carácter comunitario de la confesión": Ecclesia $34\left(1974\right.$, n. $\left.{ }^{\circ} 1.680\right)$ 248250 ; A. BugNINI, "El sacramento de la penitencia y la reconciliación con Dios": Edclesia 34 (1974, n. $\left.{ }^{\circ} 1.680\right) 251$; "Ante posibles reacciones simplistas: Nota del Arzobispado de Barcelona": Ecclesia 34 (1974, n. ${ }^{\circ} 1.680$ ) 248; "Le sacrament de la réconciliation. Le Nouveau Rituel de la pénitence": La Documentation Catholique 71 (1974, n. 1.649) 209-212; "Presentation du Nouveau Rituel Romain par le Centre National (français) de Pastorale Liturgique": La Documentation Catholique 71 (1974, n. ${ }^{\circ}$ 1.649) 212; "Interview de Mgr. Bugnini": La Documention Catholique 71 (1974 n. 1.649) 211-212; "Vivre la pénitence aujourd'hui. Orientations pastorales d'évêques français": La documentation Catholique 71 (1974, n. $\left.{ }^{\circ} 1.659\right)$ 213-215: "Extraits des Praenotanda du Nouveau Rituel Romain de la pénitence": La Documentation Catholique 71 (1974, n. 1.649) 214-217.

Considero útil extractar el índice del número que la revista española phase ha dedicado al Nuevo Ritual:

P. Tena, "Editorial": Phase 14 (1974) 4-10; J. A. Gracia, "Historia de la reforma del Nuevo Ritual (1966-1973): Phase 14 (1974) 11-22; P. FARNES, "El misterio de la reconciliación en la historia de la salvación":
\end{abstract}


Toda orientación acertada posee el dinamismo necesario y suficiente para impulsar y dirigir su desarrollo evolutivo. Sin embargo las legislaciones se ven despojadas, con frecuencia, de tal dinamismo por obra de ciertas, mal llamadas, exposiciones aclarativas. Son interpretaciones inadecuadas que producen un impacto altamente perjudicial para el contenido y finalidad de las orientaciones dadas. Esto es lo que acontece con las Normas Pastorales y, extensivamente, con el Nuevo Ritual del Sacramento de la Reconciliación, siempre que se los someta a una interpretación estrictamente jurídico-canónica.

No cabe duda que, como toda obra humana, también las Normas Pastorales presentan el adhesivo de unas imperfecciones, que se hacen más ostensibles a través de tales interpretaciones tan poco acertadas.

Que el estudio gramatical del texto forme parte integrante de su interpretación está fuera de duda, ya que el autor exterioriza sus ideas y decisiones, tomadas en un proceso racional, mediante el símbolo del lenguaje.

Pero esto no es suficiente. Habrá que acudir también a las prescripciones que las precedieron, requisito que suelen cumplir los intérpretes de las Normas Pastorales ${ }^{2}$. También se han de tener en cuenta los trabajos preparatorios de las normas y su elaboración, así como el discurrir histórico de la realidad social regulada. Esto

Phase 14 (1974) 23-30; P. FARNes, "La reconciliación de los penitentes en la vida de la Iglesia": Phase 14 (1974) 31-49; D. Borobio, "Los oficios y ministros en la reconciliación de los penitentes": Phase14 (1974) 50-65; J. CAMPs, "La celebración de la Penitencia": Phase, Ibid. 66-68; P. LLABRES, "Orden para la reconciliación de los penitentes en particular": Ibid. 69-74; D. BoROBIO, "Orden para la reconciliación de muchos penitentes con confesión $\mathrm{y}$ absolución individual": Ibid. 75-85; J. A. Gracia, "Orden para la reconciliación de los penitentes con confesión y absolución general": Ibid. 86-93; J. CAMPS, "Las celebraciones penitenciales": Ibid. 94-96; P. FARNES - D. Borobio, "Justificación de la celebración comunitaria. Reconciliación con la Iglesia": Ibid. 103-111; P. TENA, "Confesión individual. Absolución colectiva": Ibid. 112-116; J. BERNAL, "Diagnóstico sobre la crisis de la Penitencia. Información bibliográfica": Ibid. 117-135.

2. Concesiones de 6 de Febrero de 1915: AAS 7 (1915) 72 ; de 30 de Agosto de 1939: AAS 31 (1939) 719 juntamente con algunos otros casos recogidos por $\mathbf{X}$. OcHOA, Leges Ecclesiae post Codicem iuris canonici éditae, I, Roma 1967, n. ${ }^{\circ} 1.505,1.532$. Preferentemente se refieren a la proposición condenada por Inocencio XI (H. DENZINGer - A. ScHoNmeTZER, Enchiridion Symbolorum n. 2.159), y a la Instrucción de la S. Penitenciaria del 25 de Marzo de 1944: AAS 36 (1944) 155-156. 
ya lo olvidan buena parte de los intérpretes, que catalogo entre los pertenecientes a la corriente jurídico-canónica ${ }^{3}$.

Otro defecto común a todas estas interpretaciones lo constituye la poca atención prestada al contenido conceptual de vocablos, secularmente utilizados, cuyo sonido articulado y escritura se mantienen inmutables, mientras su contenido conceptual ha ido precisándose y aún está haciéndolo actualmente en función de los nuevos conocimientos de ciencias afines o conexas con la moral. Bástenos recordar los vocablos "pecado", "mortal", "de derecho divino".

Claramente practican estos autores la interpretación lógicoconstructiva caracterizada por la prevalencia concedida a lo literal sobre la ratio legis o valores que la ley trata de proteger e impulsar. Se mantienen en la desacertada tesis de que el finis legis non cadit sub lege, como si fuera un brocardo que también tuviera validez en el terreno de la interpretación.

Cambiaría considerablemente su interpretación si utilizaran la interpretación teleológica que se afana, más que en la conquista del sentido literal, aunque sin despreciarlo, en la adquisición del sentido intrínseco de la realidad regulada, aquí la realidad sacramental, integrada por la bondad salvífica del Dios que quiere comunicarse al hombre y la realidad humana cambiante que quiere aceptar esa salvación venida de Dios. El puesto de segundón que la interpretación jurídico-canónica asigna a la realidad doble del sacramento de la reconciliación priva a tal clase de interpretación de una de sus características: el dinamismo cambiante y transformante al unísono con la realidad. Es preciso que toda interpretación se mantenga atenta a descubrir cómo despliega su dinamismo el bien oculto en la ley y protegido por ella misma.

Frecuentemente la interpretación jurídico-canónica pasa por alto los silencios legislativos, a veces muy significativos y elocuentes. Concretamente en las Normas pastorales tal vez estos silencios la doten de su mayor riqueza. Sin embargo, la tendencia interpretativa, que comentamos, suele limitarse a lo que la ley dice expresamente, si bien algunos autores son conscientes de ello 4.

3. De cuantos estudios he podido controlar solamente la Revista PHASE dedica un artículo al estudio de la elaboración histórica del texto: J. A. GRAcia, "Historia de la reforma de Nuevo Ritual (1966-1973)": Phase 14 (1974) 11-22.

4. De todos los autores citados en la nota 1 al único que podemos distinguir es a K. RAHNER, "Bussandacht und Einzelbeichte. Anmerkungen 
culpa suya, a quedar privados por largo tiempo de la gracia sacramental o de la Sagrada Comunión" (Norma III).

Aventura un juicio valorativo sobre la posibilidad de existencia de este grupo de causas justificantes. Más frecuentemente se darán en territorios de misión; también, pero más raramente, en nuestros países cristianos. Sin embargo ha considerado oportuno confiar a los obispos la determinación concreta de los casos lícitos: "queda reservado al Ordinario del lugar, después de haber intercambiado su parecer con otros miembros de la Conferencia Episcopal, juzgar si se dan las condiciones señaladas en el número $\mathrm{II}, \mathrm{y}$, por tanto, decidir cuándo se puede dar la absolución sacramental colectiva" (Norma V).

En determinados casos el juzgador inmediato sobre la licitud o ilicitud, es decir, sobre la conveniencia o inconveniencia de una celebración comunitaria lo será el mismo sacerdote: "Además de los casos determinados por el Ordinario del Lugar, si se presenta otra necesidad grave de dar la absolución sacramental a muchos simultáneamente, el sacerdote está obligado a recurrir previamente al Ordinario del lugar, siempre que le sea posible, para poder dar lícitamente la absolución; en caso contrario, deberá informar cuanto antes al mismo Ordinario sobre tal necesidad y sobre la absolución" (Norma V).

Todas estas cláusulas, excepto contados autores, las interpretan restrictivamente ?

b.- No obstante tal amplitud de términos "La confesión individual y completa seguida de la absolución es el único medio ordinario, mediante el cual los fieles pueden reconciliarse con Dios y con la Iglesia..." (Norma I).

B. Sólo la interpretación teleológica permite el desarrollo y evolución práctica del contenido doctrinal de las NORMAS PASTORALES y del NUEVO RITUAL.

La interpretación lógico-constructiva y estrictamente jurídicocanónica no puede satisfacernos en si misma. Es el punto de partida, mas no debe pretender serlo de llegada. Si fuera así quedaría sometida la persona a la ley, siendo indiscutible que ésta debe estar al servicio de aquella. Sentido que cobra aún mayor alcance

7. Véase la nota 1. 
cuando nos movemos en el terreno de la ley religiosa que orienta al hombre en sus relaciones personales con Dios.

Estoy convencido de que la única manera de mantener el respeto, que se merecen tanto las Normas pastorales como el Nuevo ritual, es el darles una interpretación teleológica. $Y$ como tal no es una interpretación caprichosa, sino fundamentada en las sabias orientaciones del Concilio Vaticano II: "Revísense el rito y las fórmulas de la penitencia, de manera que expresen más claramente la naturaleza y efecto del sacramento" 8 .

Según esto toda interpretación que impida a las Normas conseguir una mejor y más clara manifestación "de la naturaleza y efecto del sacramento" será errónea, puesto que la causa de las Normas es la presionante invitación y mandato de los Padres Conciliares. Sería un contrasentido interpretar las Normas de manera que se opusieran a las orientaciones conciliares, que son su origen y fuente. $Y$ parece que la interpretación jurídico-canónica de las Normas pastorales y del Nuevo ritual no se acomoda a las indicaciones conciliares. Unicamente lo consigue, como iremos viendo, su interpretación teleológica. Y lo consigue porque ésta considera a la naturaleza y efectos del sacramento como su punto de referencia y verificación, de manera que en tanto considerará acertadas las determinaciones concretas en cuanto que visibilicen dicha naturaleza sacramental.

1.' Deficiencias de las NORMAS PASTORALES a tenor de su interpretación teleológica.

Notamos algunas deficiencias más o menos considerables.

a.-Uso de terminologia anticuada -en las NORMAS PASTORALES- o fluctuación terminológica —en el NUEVO RITUAL.

La terminología usada para la designación del sacramento y de sus efectos es la acostumbrada en nuestros manuales. Es verdad que utiliza el verbo "reconciliarse" (Introducción) que respondería perfectamente a la mentalidad actual, pero a la hora de sustantivizarlo nos encontramos ordinariamente con expresiones como "confesar sacramentalmente", "confesión" (Norma I); "oír en

8. Véase: Constitución sobre la Sagrada Liturgia n. $.^{\circ} 30,34,35,59$, 72, 109-110; Constitución sobre la Iglesia n. ${ }^{\circ} 11$; Decreto sobre el ministerio pastoral de los obispos n. $30,2 .^{\circ}$; Decreto sobre el ministerio y vida de los presbiteros n. 5 . 
confesión", "confesión individual" (Norma II, III, V, XI, XIII, VII VIII); "confesión sacramental" (Normas IX, X).

El nuevo ritual da la impresión de haber querido despegarse un poco de la terminología acostumbrada sin conseguirlo totalmente. Como que se constataran dos tendencias que se exteriorizaran en el uso fluctuante de los términos linguísticos. Así habla de "Ordo paenitentiae" y también de "misterio de la reconciliación"; de "reconciliación de los penitentes", de "reconciliarlos", de la "reconciliación y conversión como razón última de la penitencia", de "ponerlos en camino de conversión", "de que la penitencia siempre connota una reconciliación" y también del sacramento de la penitencia o simplemente de penitencia" 9.

El estudio histórico del proceso de elaboración creo que nos aclara suficientemente el por qué de la inactual terminología de las Normas pastorales y del lenguaje fluctuante del Nuevo ritual ${ }^{10}$.

9. "El Nuevo Ritual del Sacramento de la Penitencia": Phase 14 (1974) 4-116.

10. A finales de 1966 se constituye el "coetus 23 bis", para la revisión del rito del sacramento de la reconciliación. Los días 8-9 febrero 1967, en su primera reunión, se ponen de acuerdo sobre las líneas fundamentales que dirigirán su investigación y que serán las conciliares. En su primer "rapport" hacía siete preguntas sobre las que esperaban respondieran la sesión plenaria del Consilium del 13 de abril de 1967. Les responde afirmativamente. Sigue la segunda reunión del "coetus 23 bis" los días 10-11 de Mayo de 1967. Preparan dos bocetos, uno sobre la reconciliación individual y otro sobre su celebración comunitaria titulado "Celebración de la penitencia con confesión comunitaria". Faltaron varios miembros a la reunión. Ello obligó a remitirles el trabajo para que lo devolvieran con sus respectivas anotaciones. No se aludía ni decía nada sobre el valor sacramental de esta celebración comunitaria. Deseaban consultar a teólogos e historiadores "Obtenida una respuesta satisfactoria de la teologia, quedaba por consultar a la historia, cuya voz, tras minuciosos estudios de los especialistas, declaraba abiertamente dos cosas: que la práctica sacramental de la Iglesia a lo largo de los siglos no excluyó las celebraciones comunitarias sin confesión privada de las distintas formas sacramentales de la penitencia, $y$, que la obligación de confesar los pecados graves por la confesión llamada "privada" no corespondía a la tradición auténtica de antes de finales de la Edad Media. En suma: los expertos debían preparar ya definitivamente un rito de celebración del sacramento de la penitencia con absolución general para todas las situaciones que autorizara la Iglesia".

El "coetus de Paenitentia" se reun'e por tercera vez los días 6-7 de diciembre de 1967. Elabora ambos de modo definitivo el ritual completo. Se envía, con un amplio dossier a los miembros del grupo y es "sometido a las observaciones de un amplio círculo de expertos, peritos y especialistas en la materia, con cuyas sugerencias se elabora un nuevo esquema que está dispuesto el 17 de febrero de 1968". Se espera su aprobación del Consilium pleno del mes de abril de 1968. "Salió de la sesión plenaria con aires de triunfo. Hubo sólo ligeras correcciones. Habían proyectado reunirse de nuevo los días 14-15 de junio de 1968 con el fin de incor- 
Es cierto que puede individualizarse el sacramento con distintas denominaciones. Bien elocuente es el siguiente párrafo extractado de las Actas del Concilio de Trento:

"...Et primo adduxit quaedam argumenta adversariorum circa primum articulum, quod poenitentia non debeat dici sacramentum, cum Ioa. 20 nulla fiat mentio de poenitentia; sed deberet dici potius sacramentum absolutionis tanquam denominatio a digniori. Praeterea si esset sacramentum poenitentia, deberet accipi non ex Io. 20, sed ex aliis locis, ubi ea praecipitur ut Lc. 13, et Marc. 1". "Responditque ad ea quae Zagrebensis dixerat, quod hoc sacramentum vocetur multis modis, ut sacramentum confessionis, sacramentum absolutionis et sacramentum poenitentiae, quia est poenitentibus peccatoribus. Vocatur etiam et secunda tabula post naufragium. Non obstat igitur, quod dicebat Zagabrensis, quia omnibus illis modis nuncupatur" 11 .

Tanto las Normas pastorales como el Nuevo ritual si son pastorales y si querían contribuir a la renovación deseada por el Concilio estaban en el deber de seleccionar cuidadosamente el título del sacramento que nos ocupa, ya que el mismo título, aunque sea algo esencial, contribuye por sí mismo a establecer un ambiente apropiado o inadecuado a la naturaleza del sacramento. Lamentablemente la terminología empleada tanto en las Normas pastorales como en el Nuevo ritual no responde a la actual mentalidad pastoral, bien reflejada en los títulos de no pocas obras doctrinales de nuestros días ${ }^{12}$.

b.- Ausencia de realismo.

Fundamentalmente se constata cuando procura estudiar las cau-

porar dichas correcciones. No se reunieron. Se preparaba por correspondencia entre si una rúbrica que decía: "El celebrante previene a los penitentes de que, cuando tenga oportunidad, deben confesar los pecados absueltos en esta confesión general". Se sometió a la aprobación de los Padres en la sesión del Consilium en otoño de 1968. Se sigue entonces un largo período, 4 años, de absoluto silencio. En ellos se suceden los movimientos experimentales muy numerosos. Súbitamente interviene la Sagrada Congregación para la Doctrina de la Fe publicando sus Normas Pastorales el 17 de junio de 1972, cuyo tenor ya conocemos. Paralelamente la Congregación del Culto nombraba un nuevo coetus dê expertos, en el que no figuraba ninguno de los miembros del primitivo coetus. De este nuevo coetus procede el actual RITUal NuEvo, J. A. Gracia, "Historia de la reforma del nuevo ritual (1966-1973)": Phase 14 (1974) 11-22. 296.

11. Concilii Tridentini Actorum, Friburgi Brisgoviae 1961, t. VII, 295,

12. R. GRAF, Il sacramento della divina misericordia, Brescia 1958; B. Haring, Confessione e gioia, Pescara 1963; M. Mellet, La penitence sacrement d'amitié, Paris 1954; S. MagGrolinI, El pecado y el perdón en la comunidad eclesial, Madrid 1973. B. HARING, Schalon: Paz. El sacramento de la reconciliación, Barcelona 1971; P. JOURNEL, "La liturgie de la reconciliación": Maison-Dieu n. ${ }^{\circ} 117$ (1974, 10) 7-37. 
sas de la desafección que sienten los fieles por este sacramento. Las Normas pastorales parecen aludir únicamente a la escasez de confesores con la molestia consiguiente de la demora y pérdida de tiempo. Tanto es así que trata de solucionarlo en varias Normas urgiendo el celo pastoral de los sacerdotes ${ }^{13}$. Bastaría, por el contrario un somero hojear los escritos doctrinales y las encuestas realizadas para cerciorarse que las causas son muy numerosas y bastante más complejas que la siemple e ingénua escasez de confesores ${ }^{14}$.

Hasta podemos decir que podemos apreciar un irrealismo impracticable, cuando se lee el orden de la reconciliación individual plasmado nada menos que en un Nuevo ritual ${ }^{15}$.

Otro tanto podriamos decir en cuanto a los errores a que aluden las Normas pastorales y que subdivide en teóricos y prácticos ${ }^{16}$.

13. Acta Apostolicae Sedis 14 (1972) 510-514.

14. "Les chrétiens parlent de la confession": La Vie Spirituelle n." 555 (1968) 375-500. F. G. SvIdercoschI Inchiesta sulla confessione, Milano 1972; F. NIKolash, "Zur Erneurung der Liturgie des Bussakramentes": Heiliger Dienst 22 (1968, n. 4) 126 ; L. LOCHET, "Degradations et renouvelement du sacrament de pénitence": Foi et Temps (1968, n. 6 ) 557; J. NEsMY, Práctica de la confesión, Barcelona 1967; Augusten, "Der Mensch im Beichgeschehe": Lebendige Seelsorge 2 (1972) 37-42; J. MEYER-SchnEE, "Entwertung der Sünde Gefährdung des Bussakramentes": Anzeiger für die katholische Geistchkeit 75 (1966, n. $\left.{ }^{\circ} 6\right)$ 250; VARros, "La penitencia en

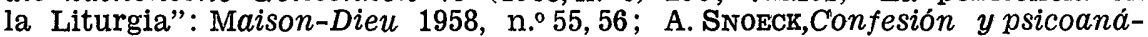
lisis Madrid 1959; F. SEBastian, J. R. ScheIfFler, Para renovar la penitencia y la confesión, Madrid 1969; F. J. HEGGEN, La penitencia acontecimiento dé salvación, Salamanca 1969; E. LodI, "Le celebrazioni comunitarie della Penitenza nella loro prospettiva liturgico-pastorale": Rivista Liturgica 54 (1967, n. ${ }^{\circ}$ 5) 643-644; K. TILLMANN, La penitencia y la confesión, Barcelona 1967; B. Haring, "La Pastorale du milieu dans le sacrament de pénitence": Pastorale entré hier et demain, Lyon 1962; J. H. Nrcolas, "Tes péchés sont remis": Vie Spirituelle (1967, n. 538) 504 504; P. JACQUEMONT, "Des laïs redécouvrent le sacrament du pardon": Vie Spirituelle (1967, n. ${ }^{\circ}$ 538) 525; "Propos sur la confession": Vie' Spirituelle (1967, n. 538) 110; L. Berscht, Penitencia y confesión, Madrid 1969; K. RAHNER, Escritos de Teología III, C. E. CURRAN, ¿Principios absolutos en Teologia Moral?, Santander 1970, 32-33, 135; P. ANciaux, "Confession privée et celebration communautaire de la pénitence": Colléctanea Mechlinensia (1966, n. ${ }^{\circ}$ 51) 609-610; C. J. NESMY, "Worüber sich anklagen"? Heiliger Dienst 22 (1968, n. 4) 130; O'CONNELI, "La teología sacramental hoy": Selecciones de Teología 2 (1963) 29-36.

15. Sagrada Congregación para el Culto Divino: Nuevo Ritual de la penitencia: IV, A. Ordo para reconciliar a los penitentes en particular: Preparación del sacerdote y del penitente; recepción del penitente; lectura de la palabra de Dios; confesión de los pecados y aceptación de las satisfacción; oración del penitente y absolución del sacerdote; acción de gracias y despido del penitente. Rito más breve.

16. Introducción a las NoRMas Pastorales. 


\section{c.- Objetivismo.}

Todas las causas excusantes de la que se considera forma ordinaria de reconciliación, la individual, son exclusiva o prevalentemente objetivas, de carácter objetivo. Es verdad que la Norma I menciona tanto la imposibilidad moral como la física. Más en las Normas siguientes se afana en precisar el concepto de imposibilidad física, invita a los Obispos a determinar en qué casos se da tal imposibilidad; pero guardan el más absoluto silencio en lo referente a la imposibilidad moral. Y sin embargo es bastante más costoso, por lo que estábamos más necesitados de orientaciones sobre la imposibilidad moral que de tales precisiones en torno a la imposibilidad física.

Si nos atenemos a lo que dicen expresamente las Normas pastorales y si consideramos su enumeración como exhaustiva en cuanto a los límites, incurriríamos en la contradicción de denunciar, por una parte, la imposibilidad moral (Norma l) y, sin embargo, no concederla valor alguno, por otra parte, a consecuencia del silencio con que la cubren las Normas siguientes.

No podemos olvidar, a la hora de hablar de su objetivismo, que el juicio sobre los casos en que sea conveniente y lícito las celebraciones comunitarias sacramentales queda primariamente sometido al obispo "intercambiando su parecer con otros miembros de la Conferencia Episcopal" y secundariamente y en casos excepcionales al sacerdote (Norma $V$ ).

De aquí el objetivismo aparente y también el juridicismo de las Normas pastorales. Sin embargo opino, como indicaré más adelante, que cabe otra interpretación en la que posea el valor que le corresponde la imposibilidad moral, entendida en sentido estricto.

d.- Olvida el principal problema pastoral: ¿Cuándo se da el pecado mortal?

Las Normas reproducen textualmente las palabras del Concilio de Trento ${ }^{17}$. Pero el Concilio de Trento no da claramente una definición del pecado mortal ${ }^{18}$. Tampoco las Normas. Por tanto, al no

17. Introducción a las NoRmas Pastorales; Norma I.

18. Cfr. H. Vorgrimiler, "Das Bussakrament -iuris divini"? Diakonia 4 (1969, n. 5) 257-266; Z. HERRERo, "La penitencia y sus formas. Examen de su evolución histórica": Estudio Agustiniano 8 (1973) 268-270. 
tener una determinación oficial, hemos de acudir a las corrientes doctrinales aprovechando cuantas aportaciones nos ofrezcan. A través de ellas podemos entrever cómo ha ido elaborándose el concepto de "pecado mortal" y cómo mediante el aumento, lento, pero constante, del número de pecados que había que someter al poder de las llaves, se llegó a la equiparación del pecado grave al pecado mortal. Conviene recordar las discusiones existentes actualmente sobre el pecado como acto o como actitud, sobre su división bipartita o tripartita (venial-grave-mortal) ${ }^{19}$, sobre los criterios, anteriormente de corte jurídico impositivo y derivados de las ciencias naturales con un objetivismo asfixiante: pesas y medidas (pecado grave y leve, onzas, tiempo mayor o menor...), y hoy de corte personalista y tomados más bien de las ciencias psicológicas y antropológicas en general (opción fundamental) ${ }^{20}$. No

19. G. Higuera, "Los puntos teológicos-morales discutibles del Catecismo Holandés": Sal Terrae 59 (1971) 83-100; M. V. FERRARI, "Peccato mortale e veniale": Rivista di Teología Morale 2 (1970, n. 2) 53-66; HuBERT, "Responsabilidade colletiva e peccato": Revista Eclesiastica Brasileira 30 (1970) 538-567; G. HIGUERA, "Pecado mortal y pecado grave": Sal Terrae 56 (1968) 134; Monden, La conscience du péché, París 1965; RamosREGIDOR, Il sacramento della penitenza; K. RAHNER, "Sünde und Gnadenverlust in der frühchristlichen Literatur": Zeitschrift dür Katholische Theologie 60 (1936) 471-510; MORENo, "Pecado e historia de salvación (Rom. 1-3)": Téología y Vida 13 (1972, n. $\left.{ }^{\circ} 1-2\right)$ 39-55; SANCHEz, "Las categorias del pecado venial": Studium 12 (1972) 320-332; ID., "Sobre la división del pecado": Studium 14 (1974) 119-131; HarING, "Pecado mortal y pecado venial": Pentecostés 11 (1973) 5-24; J. L. LARRABE, "Pecado mortalpecado venial": Lumen 9 (1960) 237-246.

20. MONDEN, Conscience du péché, Paris 1965; Ramos-REgIdor, Il sacramento della penitenza. J. TAYLOR y Otros, El misterio del perdón y del pecado, Santander 1972; Schuller, BertSch, Roth, SEMmelrot, Penitencia y confesión, Madrid 1969; K. RAHNER, Sünde und Gnadenverlust in der frühcristlichen Literatur": Zeischrift für Katholische Theologie 60 (1936) 471510; M. V. FERRARI, "Pecato mortale e peccato veniale": Rivista di Teología Morale 2 (1970, n..$^{\circ}$ ) 53-60; SchulLER, "Todsünde zum Tod"?: Theologie und Philosophie 42 (1967) 321-340; G. HIGUERA, "Los puntos teológicomorales discutibles del Catecismo Holandés": Sal Terrae 59 (1971) 83-101; 60 (1972) 689-672; J. M. CASABo, La Teología Moral en S. Juan, Madrid 1970, 413-416; G. EBeLING, Theologische Erwägungen über das Gewissen": Wort und Glaube, 2." edi. 1962, 429-446; U. Rocco, "opzione fondamentale e singoli atti": Perfice Munus 45 (1970) 460; RaMos-REGIDOR, "Opzione fondamentale e singoli atti" in Adolescenti e Penitenza, Torino 1969, 1367; B. Russo, "Peccato mortale: eccezione o inflazione"?: Rassegna di Teologia 12 (1971) 85; S. MAGGIOLINI, El pecado y el perdón en la comunidad eclesial, Madrid 1973; Fuchs, Theologia moralis generalis. Pars Altera ad usum privatum auditorum, Roma 1967-8, 3-8, 15-18, 59-62, 131-157; M. SANCHEz, "Por una división tripartita del pecado": Studium 10 (1970) 340358; G. HIGUERA, "Pecado mortal y pecado grave": Sal Terrae 56 (1968) 132-139; L. BABBinI, "L'opzione fondamentale per Dio": Palestra del Clero 49 (1970) 286-292; A. GALLI, "L'opzione fondamentale del personalismo 
cabe duda que todos estos son temas doctrinales y pastorales de mayor relevancia a los elegidos en las Normas pastorales, y de los que depende la interpretación que se haya de hacer de las Normas. Aunque hemos de reconocer que éste sería uno de esos silencios valiosos ya que gracias a él no hemos de lamentar la interrupción de la libertad de que gozamos ahora en medio de las discusiones doctrinales.

Parece ignorar un concepto tan fundamental y alentador, hoy en día, como es el de conversión progresiva ${ }^{21}$. En cuanto al examen habría sido muy positivo si hubiera hecho alusión, dejando a un lado viejos esquemas, a algunos temas, ya aludidos por el Concilio, en los que el hombre de nuestros días se siente especialmente pecador: el amplio campo de las relaciones con los demás, ante todo, en aquello que entorpece la marcha ascendente hacia una comunidad humana más igualitaria. No podemos olvidar que lo importante es que el hombre se sienta pecador y necesitado del Dios tres veces santo. Las esferas de la vida, a través de las cuales el hombre cristiano llega a esta convicción, varian a lo largo de la historia: antes fue el campo de la impureza, ahora parece ser el de la injusticia social y el egoísmo. El pastoralista ha de estar en permanente contacto con la realidad pecaminosa vivida y sentida por el hombre para poder ayudarle con sus orientaciones.

También cabía esperar un enfoque más constructivo del propósito orientado hacia el futuro y acentuando el compromiso activo del cristiano-convertido en la expansión del Reino de Dios y en el hacer visible a Cristo en la propia vida ${ }^{22}$.

esistenzialistico": Palestra del Clero 20 (1970) 927-937; RuF, Sünde, Was ist das?

21. B. Haring, La moral y la persona, Barcelona 1973; W. HeIneN, Fundamentos de una moral cristiana, Madrid 1972; P. ANcIaux, F. D'Hoogh, J. GHoos, El dinamismo de la moral cristiana, Salamanca 1971; Ch. Curran, ¿Principios absolutos en Teología Moral?, Santander 1970; F. WETER, "Busse, Sakrament, christliches Leben": Geist und Leben 46 (1973) 333-348; TuRck, "L'Eglise comme peuple de Dieu et sacrament de pénitence": Paroisse et Liturgie n. 3 (1966) 255-260; C. PlanA, "Il messagio della conversione nelle liturgia quaresimale": Rivista Liturgica 4 (1973) 4 (1973), n. ${ }^{\circ}$ 1) $45-57$; D. SARTORE, "La quaresima, tempo forte della conversione della Chiesa": $R$. Liturgica 4 (1973) 69.

22. F. Sebastian, J. R. Scheiffler, Para renovar la penitencia y la confesión, Madrid 1.969; VARIOS, Pastorale entre hier et demain, Lyon 1962 ; F. J. HEGGEN, La penitencia acontecimiento de salvación? Salamanca. K. Tillmann, La penitencia y la confesión, Barcelona 1967. 
Y iqué alegría nos habrían proporcionado si en las Normas pastorales hubiéramos podido descubrir aquella sabiduria pastoral mostrada por los misioneros de las Islas, quienes, al comprender las dificultades y poca eficacia de la forma continental de celebrar la reconciliación, se esforzaron y acertaron a crear una forma adaptada a las necesidades y mentalidad de sus convertidos! ${ }^{23}$. Por todo no es exagerado que concluya Rahner afirmando que estas Normas, aunque sean adjetivadas como Pastorales, en realidad no lo son. Son producto de escuela, pero no de la escuela en contacto con la realidad vivencial del hombre de la calle, que es el cristiano y sobre quien inciden sus consecuencias.

2. Conclusiones de la interpretación teleológica de las NORMAS PASTORALES y del NUEVO RITUAL.

a.-Debe hacerse una interpretación extensiva de las Normas.

Las Normas pastorales constituyen a la confesión individual, tal como la hemos aprendido de niños, como el medio ordinario de reconciliación, mientras que a la forma comunitaria, sin confesión detallada y con absolución colectiva, sólo le conceden la categoría de forma extraordinaria (Norma 1). Esto inclina a varios autores, lo mismo que se echa de ver en algunas intervenciones de los obispos, a dar una interpretación restrictiva a las Normas. No considero acertado tal raciocinio porque el calificativo de "ordinario", tiene ante todo una significación teológica y no necesariamente numérica o estadística. Hay en la Iglesia muchas situaciones "ordinarias" que no son, sin embargo, las más frecuentes. Las hay de todos tipos, desde el hecho de la existencia del pecado, pasando por la participación en la Sagrada Comunión de los que toman parte en la celebración de la Santa Misa, hasta la celebración del matrimonio o de la confirmación dentro de la liturgia eucarística. Se trata evidentemente de analogías en que el derecho divino está implicado en forma muy diversa. En el caso que nos ocupa, las circunstancias revisten gran relieve y podrían llegar a justificar (sin hacer en modo alguno violencia al texto de

23. Z. HERrero, "Anotaciones sobre la evolución histórica de las formas de penitencia con las que se exteriorizaba el perdón de los pecados": El Sacramento de la penitencia $X X X$ Semana Española de Toledo (Madrid, 14-18 sept. 1970), Madrid 1572, 223-250. 
las "Normas") que el "único modo ordinario" no fuera en la práctica el más frecuente en ciertos lugares" ${ }^{24}$.

$Y$ en cuanto a las mismas Normas hemos de observar que no podrán urgir más que el mismo Concilio Tridentino y estarán sometidas a las mismas dificultades, puesto que se fundamentan en el citado Concilio. Por otra parte es imposible, aunque se intente, despojar a las Normas de su tendencia extensiva, no solamente frente a la Instrucción de $1944{ }^{25}$, sino también por su mismo contenido. No propone lista alguna taxativa de casos en que se puede lícitamente hacer celebraciones comunitarias sacramentales. Expone simplemente los límites dentro de los cuales han de encontrarse todos los posibles casos, pero su determinación la encomienda a los obispos "después de haber intercambiado su parecer con otros miembros de la Conferencia Episcopal..." (Norma $V$ ). Y si esto fuera poco aún prevé que existirán casos no abarcados por el celo pastoral de los obispos, pero sí por los sacerdotes que viven y dirigen al reducido grupo eclesial. "Además de los casos determinados por el Ordinario del lugar, si se presenta otra necesidad grave de dar la absolución sacramental a muchos simultáneamente, el sacerdote está obligado a recurrir previamente al Ordinario de lugar, siempre que le sea posible, para poder dar lícitamente la absolución; en caso contrario, deberá informar cuanto antes al mismo Ordinario sobre tal necesidad y sobre la absolución dada" (Norma V).

$\mathrm{Ni}$ se opone esta interpretación al "salva illorum substantia" del Concilio Tridentino, puesto que, como he tratado de demostrar en artículos anteriores, la confesión detallada no es algo substancial al sacramento sino una forma de realizar la reconciliación ${ }^{26}$. Aparte las dificultades de probar tanto la presencia como la no existencia de la confesión detallada en los primeros siglos, nos encontramos con que la Iglesia asegura perdonar los pecados en determinados casos que ahora amplían estas Normas pastorales.

24. J. Medina, "Un nuevo documento de la $\mathbf{S}$. Sede sobre el sacramento de la penitencia": Teología y Vida 13 (1972) 109-110.

25. Ampliamente demostrado puede verse en H. WAGNoN, "Les "Normae pastorales" pour l'administration de l'absolution sacramentelle générale": Revue Théologique de Louvain 4 (1973) 46-57.

26. Z. HERRERo, "La penitencia y sus formas. Exámen de su evolución histórica": Estudio Agustiniano 6 (1971) 3-32; (1972) 37-71, 231-254, 549-574; 8 (1973) 253-270. 
Jamás, en cambio, podrá perdonar sin la conversión. Ni podemos olvidar que los técnicos de la historia de los dogmas y también los teólogos, que asesoraron al primer "coetus" encargado de la reforma, concluyeron que no había dificultades que oponer al cambio proyectado ni desde el punto de vista histórico ni desde el dogmático ${ }^{27}$.

b.- La interpretación teteológica admite la imposibilidad moral como justificante de las celebraciones comunitarias sacramentales.

Esta imposibilidad existe realmente no sólo en algunos cristianos particularmente considerados, sino en grandes grupos de personas mayores y de juventud, sobre todo entre la universitaria. Las encuestas realizadas vienen a indicarnos que, frente a la forma actual de reconciliación, estamos viviendo la misma borrasca que experimentó la Iglesia frente a la forma pública que dio paso a la penitencia individual ${ }^{28}$. La simple lectura del artículo de Ch. Duquoc, "Reconciliación real y reconciliación sacramental" nos convencerá de que no se trata de sentimentalismos $^{29}$.

¿Qué nos dicen las propias Normas pastorales? Encontramos esta afirmación decidida: "La confesión individual y completa seguida de la absolución es el único medio ordinario, mediante el cual los fieles pueden reconciliarse con Dios y con la Iglesia, a no ser que una imposibilidad física o moral los dispense de tal confesión" (Norma l). Parecería claro el valor de la imposibilidad moral, pero quien busque su explicación en las Normas siguientes concluirá que hacen referencia única y exclusivamente a la imposibilidad física:

"Puede suceder de hecho que alguna vez, en circunstancias particulares, sea lícito e incluso necesario dar la absolución de modo colectivo a muchos penitentes sin previa confesión individual.

"Puede ocurrir esto, sobre todo cuando se presenta peligro in-

27. J. A. Gracia. "Historia de la reforma del nuevo ritual (19661973): Phase 14 (1974) 11-22.

28. Z. HERRERO, a. c.

29. Cfr. Concilium n. ${ }^{\circ} 61$ (1971) 23-34. 
minente de muerte $y$ no hay tiempo para que el sacerdote, o sacerdotes, aunque estén presentes, puedan oír en confesión a cada uno de los penitentes (Norma II).

"Además de los casos de peligro de muerte, es lícito dar la absolución sacramental a muchos fieles simultáneamente, confesados sólo de modo genérico, pero convenientemente exhortados al arrepentimiento, cuando haya grave necesidad; es decir, cuando visto el número de penitentes, no haya disposición de suficientes confesores para escuchar convenientemente la confesión de cada uno en un tiempo razonable, $\mathrm{y}$, por consiguiente, los penitentes se verían obligados, sin culpa suya, a quedar privados por largo tiempo de la gracia sacramental o de la sagrada Comunión" (Norma III).

Otro tanto sucede cuando se trata de solucionar la imposibilidad. Todos sus consejos se reducen a estimular y urgir a los sacerdotes su obligación de estar siempre dispuestos a cumplir su misión de forma que "no sea insuficiente el número de confesores por el hecho de que algunos sacerdotes descuiden este noble ministerio, dedicándose a asuntos temporales o a otros ministerios menos necesarios, sobre todo si éstos pueden ser ejercidos por diáconos o seglares idóneos" (Norma IV).

"Para que los fieles puedan satisfacer fácilmente la obligación de la confesión individual, procúrese que haya en las iglesias confesores disponibles en días y horas determinadas, teniendo en cuenta la comodidad de los fieles..." (Norma IX).

"Por lo que se refiere a la práctica de la confesión frecuente o de "devoción", los sacerdotes no disuadan de ella a los fieles..." (Norma XII).

Tal insistencia en la imposibilidad física lleva, casi espontáneamente a defender que solamente son lícitas y sacramentales las celebraciones comunitarias, cuando exista imposibilidad física, pero no cuando la imposibilidad sea moral. Sin embargo la Norma I admite la imposibilidad moral y hemos de concederle valor no solamente en cuanto a uno en particular -causas excusantes de la integridad-, sino también en cuanto a grupos-celebraciones sacramentales comunitarias lícitas.

No argumento partiendo de "la grave necesidad" aducida por la Norma III, porque a continuación identifica la "grave necesidad" 
con la imposibilidad física: es decir, "cuando, visto el número de penitentes, no hay disposición de suficientes confesores para escuchar convenientemente la confesión de cada uno en un tiempo razonable, y, por consiguiente, los penitentes se verían obligados, sin culpa suya, a quedar privados por largo tiempo de la gracia sacramental".

El argumento lo deduzco de la adecuada relación que ha de establecerse entre la Norma I y las II, III, IX, y X. La Norma I enuncia un verdadero principio general con todas sus atribuciones, mientras que las demás Normas citadas son una explicitación de dicho principio, debiendo someterse al contenido de la Norma I. Por tanto, nos atendremos a las Normas II, III, IX, X en cuanto expliquen el principio general contenido en la $\mathrm{I}$; en cuanto le silencien el principio sigue en vigor y habrá de aceptarse la exposición común que la doctrina hace de la imposibilidad moral, y además entendida en sentido amplio, puesto que tal es el tenor dominante en las Normas pastorales.

c.- Las anteriores conclusiones obligan a los Obispos a trabajar y emplearse con honradez en un trabajo que responda cumplidamente a la invitación de Roma que, precisadas las condiciones generales en las Normas I, II, y III, encomienda a su responsabilidad -ahí tienen un campo de ejercicio de su colegialidad- la determinación de los casos en que puedan y sean aconsejables las celebraciones comunitarias sacramentales en sus respectivas diócesis. Quizás sea conveniente recordar con frecuencia la valiosa Norma $V$ :

"Queda reservado al Ordinario del lugar, después de haber intercambiado su parecer con otros miembros de la Conferencia Episcopal, juzgar si se dan las condiciones señaladas en el número III y, por tanto, decidir cuándo se puede dar la absolución colectiva.

No creo que los obispos puedan sentirse liberados de esta obligación eclesial con una cómoda declaración de que en sus propias diócesis no se dan las condiciones emanadas de la Congregación para la Doctrina de la $\mathrm{Fe}^{30}$. Roma admite que se den comu-

30. K. RAHNER, "Bussandacht und Einzelbeichte. Anmerkungen zum römischen Erlass über das Bussakrament": Stimmen der Zeit 97 (1972) 363-372. 
nidades eclesiales no necesitadas de estas celebraciones comunitarias. Pero las encuestas indicadoras del malestar experimentado por muchos cristianos y la imperfección de los ritos reconocida por el Concilio excluyen, me atrevo a decir, que no exista ninguna circunstancia en la que sea obligado cumplimiento el recurso a tales celebraciones comunitarias. Esperamos, pues, que nuestros obispos, asesorados por pastoralistas y teólogos, conviertan en centro de alguna de sus serias y sensatas reflexiones a esta Norma $V$.

E insisto sobre este punto porque lo considero fundamental en el camino que se vislumbra como necesariamente a recorrer en el futuro. Soy de la opinión de que Roma no ve con malos ojos las penitencias sacramentales comunitarias; intuye que al igual que la fuerza del pueblo cristiano consiguió el significativo e importante paso de la penitencia pública a la entonces llamada tarifada, así logrará ahora también la implantación de la libertad responsable de poder celebrar el misterio de la reconciliación bien en la forma ordinaria -reconciliación tal como la hemos celebrado desde niños-, bien en esta forma extraordinaria - penitencias comunitarias sacramentales. El tiempo será testigo porque no en vano la historia se repite y Dios quiera que nuestra resistencia o inoperancia no se convierta en fuente abundante de inquietudes y zozobras en los corazones cristianos.

También considero que la Congregación procede con un gran tacto pastoral. Es consciente de que una liberalización absoluta, sin preparación alguna del pueblo cristiano, de las celebraciones comunitarias sacramentales fácilmente desorientaría a buen número de cristianos. De ahí que haya encomendado al celo y experiencia pastoral de los obispos la actualización de tales celebraciones y que busque la preparación, una preparación tal del pueblo, que soslaye los posibles efectos perniciosos.

A nosotros los sacerdotes nos corresponde evitar los extremismos, tanto la no aceptación de estas celebraciones, como su práctica incondicional y absoluta no admitiendo o poniendo dificultades a la celebración individual y detallada. Hemos de estar dispuestos a celebrar con los fieles la reconciliación de aquella forma que a ellos les resulte más provechosa.

Con esta disponibilidad en los sacerdotes, con la honradez en los obispos empeñados en una tarea constructiva y con la aplica- 
ción de la Norma $V$ podemos dar un paso muy provechoso en la educación y vivencia cristiana del pueblo fiel.

Si los obispos no cumplieren con su misión o la cumplieren contraviniendo a la realidad pastoral, entrará en acción la última parte de la Norma $V$ :

"Además de los casos determinados por el Ordinario del lugar, si se presenta otra necesidad grave de dar la absolución sacramental a muchos simultáneamente, el sacerdote está obligado a recurrir previamente al Ordinario de lugar, siempre que le sea posible, para poder dar lícitamente la absolución; en caso contrario, deberá informar cuanto antes al mismo Ordinario sobre tal necesidad y sobre la absolución dada".

Está bien recordar estas líneas de K. Rahner: "No es extraño ni verdaderamente peligroso el que una instrucción no infalible del oficio pastoral de la Iglesia, a pesar de la fuerza verdaderamente obligante que la compete, deba ser confiada al juicio moral del particular, a quien no se le puede ahorrar el juzgar si esta Instrucción le obliga o no hic et nunc. Sería inmoral si quisiera servirse el particular de esta afirmación para sustraerse a la dirección práctica del oficio pastoral de la Iglesia, siempre que una instrucción no resultase de su agrado" 31 .

Zacarías Herrero

31. K. RAHNER, Fondamenti della teología pastorale, Roma-Brescia 1969, 142 